\title{
The Creation of the World in the Sefer Yetzirah
}

\section{Amelia Carolina Sparavigna'}

${ }^{1}$ Department of Applied Science and Technology, Politecnico di Torino, Torino, Italy

\begin{abstract}
The Sefer Yetzirah is the "Book of Creation", one of the earliest extant texts about the creation of the world of the Jewish tradition, a book that some scholars are supposing of an early Medieval origin. The Sefer tells the origin of the world as it was revealed to Abraham, in a cosmogony based on numbers and letters of the alphabet, through their combinations and permutations. The reading of this book can be interesting for a comparison to the thoughts of some medieval philosophers, Al-Farabi, Ibn Gabirol, Robert Grosseteste and others, about the primordial point and its spatial extensions.
\end{abstract}

Keywords: Cosmogony, Ancient cosmology.

\section{Introduction}

The Sefer Yetzirah, the "Book of Creation", is one of the earliest extant book of a Jewish tradition about the creation of the world. In Hebrew, "Yetzirah" can mean either "creation" or "formation", but can also refer to the created or formed object itself [1].

About the origin of this book, it was asserted that the Biblical patriarch Abraham was the recipient of the divine revelation collected in it, so that the rabbis of the classical rabbinic era never doubted that Abraham was the author of the Sefer [1,2]. According to modern historians, the origin of the text is unknown: some scholars are supposing an early Medieval origin of it, while others emphasize earlier traditions appearing in the book $[1,3]$.

The reading of this book can be interesting for a comparison to some medieval texts concerning the origin and creation of the world, for instance, the thought of Al-Farabi, Avicenna, Ibn Gabirol, or to the light metaphysics of Robert Grosseteste, that he discussed in the treatise entitled De Luce [4]. For what concerns Grosseteste, it is also interesting a comparison of the Sefer to his treatise on the generation of sound and phonetics [5]. In general, the knowledge of the Sefer is of great importance to any inquire on medieval cosmogonies, concerning the primordial point and its spatial extensions.

In this paper we report some discussions about the Sefer Yetzirah. After, we will read some parts of English translations of it [6,7], translations that we can find in the public domain.

\section{Number and letters}

The Sefer Yetzirah is devoted to speculations concerning God's creation of the world. The book describes how the universe was created by God through thirty-two "ways of wisdom", that is the ten enumerations (Sefirot) and the twenty-two letters of the Hebrew alphabet. The twenty-two letters are divided in three "mother" letters (Aleph, Mem, Shin), seven "doubles", (Bet, Gimel, Dalet, Kaph, Pe, Resh, Taw), and twelve "simples" or "elementals" (He, Waw, Zayin, Heth, Teth, Yodh, Lamedh, Nun, Samekh, Ayin, Tsade, Qoph) [1]. These divisions correspond to some concepts such as the 3 letters of the name of God, the 7 days of the week, the 12 tribes of Israel and the 12 months of the calendar. However, there are also the early philosophical ideas such as 3 elements (fire, water, air), 7 planets, 10 directions, the 12 zodiacal constellations and various human physical functions and parts of the body [1]. The book describes how God used 10 Sefirot and 22 Letters and finally how he revealed this secret to Abraham as a covenant with him. Both the macrocosm, the world, that is the universe, and the microcosm, that is the human being, are viewed in this system as products of the combination and permutation of these characters. The linguistic theories of the author of the Sefer Yetzirah are an integral component of his philosophy; other parts of the book are from astrological and Gnostic cosmogony [1,2]. The three letters Aleph, Mem, Shin, are not only the three "mothers" from which the other letters of the alphabet are formed, but they are also symbolical figures for the three primordial elements of the existence $[1,2]$.

\section{Spirit, air and cosmos}

As told in Job 33:4, "the Spirit of God hath made me, and the breath of the Almighty hath given me life". In the Sefer Yetzirah, it is the same for the creation of the world. The first emanation from God was the Spirit or Air. This spirit produced water, which, in its turn, generated the fire. In the beginning, however, these three substances had only a potential existence, and came into actual being only by means of the three letters Aleph, Mem, Shin. These are the principal 
parts of speech, so those three substances are the elements from which the cosmos has been formed $[1,2]$.

The cosmos consists of three parts: the world, the time, and the human being. These three parts contains the three primordial elements. The water formed the earth; heaven was produced from the fire; and the Spirit produced the air between heaven and earth. The time is given by the year and its three seasons, winter, summer, and the rainy season, which correspond to water, fire, and air. In the same manner, the body of a human being consists of a head, torso and the other parts of the body, equivalent to water [1,2]. In the creation of the cosmos, matter consists of the three primordial elements, which are connected and can be modified physically.

The seven double letters produced the seven planets, the seven days, and the seven apertures in man (two eyes, two ears, two nostrils, and one mouth). As the seven double letters vary, being pronounced either hard or soft, so the seven planets are in continuous movement, approaching or receding from the earth. The seven days, were created by the seven double letters because they change in time according to their relation to the planets $[1,2]$. For what concerns the twelve "simple" letters, they created the twelve signs of the zodiac, and to them belong the twelve months in time. Power (in Greek, dunamis) emanates from the seven and the twelve heavenly bodies, or, in other words, from the planets and the signs of the zodiac $[1,2]$. There is also a "dragon", probably the constellation of Draco, which represents the cosmic axis, that is the axis of the world; this constellation coils around the North Star and thus around the celestial axis, where it is intersecting the celestial sphere $[1,2]$.

Therefore, the Sefer Yetzirah aimed to harmonize the Biblical creation "ex nihilo" with the doctrine of the primordial elements [1,2], through the ten Sefirot which are ideal objects. Moreover, as the numbers from two to ten are derived from the number one, so the ten Sefirot are derived from One, the Spirit of God. This One is not only the commencement but also the end of the Sefirot. "The decade of existence out of nothing has its end linked to its beginning and its beginning linked to its end, just as the flame is wedded to the live coal". Hence the Sefirot, must be viewed as modifications of the Spirit of God, which first changes to air, then becomes water, and finally fire $[1,2]$.

Besides these ten Sefirot, the twenty-two letters of the alphabet produced the material world, for they are real, and are the formative powers of all existence and development. "By means of these elements the actual creation of the world took place, and the ten
Sefirot, which before this had only an ideal existence, became realities ... The letters are neither independent substances nor yet as mere forms. They seem to be the connecting-link between essence and form. They are designated as the instruments by which the real world, which consists of essence and form, was produced from the Sefirot, which are merely formless essences" [1,2].

\section{Gnostic elements}

According to Reference 1, the Sefer Yetzirah is similar to various Gnostic systems. As the Sefer Yetzirah divides the Hebrew alphabet into three groups, "so the Gnostic Marcus divided the Greek letters into three classes, regarded by him as the symbolic emanations of the three powers which include the whole number of the upper elements" $[1,2]$. In the Sefer and in the thought of Marcus, combinations and permutations of letters are used in explaining genesis and evolution of multiplicity from unity. Another point of agreement is in viewing God not only the beginning but also the end of all things, and that spirit of God was transformed into "pneuma", and this into water, which becomes fire and rocks, thus agreeing with the Sefer Yetzirah $[1,2]$.

As told in [8], about the connections between the Sefer Yetzirah and the Gnostic system, Shlomo Pines, a scholar of Jewish and Islamic philosophy, proposed the Pseudo-Clementine Homilies as a possible source of influence on Jewish traditions, in particular for the elaboration of spatial extension of the point in the process of emanation [9]. In examining the mystical ideas on "point, language and universe", besides the Pseudo-Clementine, Reference 8 is also suggesting a comparison to Gikatilla's speculations in Ginnat 'Egoz on the primordial point and its spatial extensions.

The Pseudo-Clementine tells that "preceding from Him, as from the Center, an essence abounding in life-giving and incorporeal force traverses all things, the stars and the adobes of heaven, the water, the earth, the fire and whatever else, if anything exists. This Essence is infinite in the direction of height, limitless in the direction of depth, immeasurable in the direction of breadth, and extended thus in a threefold manner into the infinite, life-creating and rational nature that proceeds from Him. For that which proceeds from Him must necessarily be infinite on all sides, having as its heart Him who in reality is in His shape above all things; wherever He may be, He is as it were, in the infinite as its midmost point, being the limit of the All. Therefore the Extensions, which start out from Him, have the nature of six limitless ones. One of them, proceeding from Him as its starting point, goes on towards the height above, another toward the depth below, the 
third towards the right, the fourth towards the left, the fifth forwards, the sixth backwards, and he, looking upon them as upon a number that is equal to all sides, completes the cosmos by means of six intervals of time. He being the Repose, and having the Aeon-tocome as His image; He is the Beginning and the End. For in Him the six infinite ones end, and from Him they take their extensions towards the infinite. This is the mystery of the Seven" [8].

The six Sefirot, or the limitations of space by the three dimensions in a twofold direction, are found then in the Pseudo-Clementine, where God is described as the boundary of the universe and as the source of the six infinite dimensions $[1,2]$.

\section{Isidor Kalisch and his translation of Sefer Yetzirah}

In 1877, Isidor Kalisch (1816-1886), an American reform rabbi and writer, published an English translation of the book, which is available at [6]. In the preface, Kalisch defined the book as a metaphysical essay, but "the time of its composition and the name of its author have not yet been ascertained, despite of the most elaborate researches of renowned archaeologists. Some maintain that this essay is mentioned in the Talmud treatise Sanhedrin, .. Hence this book was known already in the second or at the beginning of the third century of the Christian Era. Dr. Zunz, the Nestor of the Jewish Rabbis in Europe, maintains that we have to look for the genesis of the book Yetzirah in the Geonic period, (700-1000), and that it was consequently composed in a post-talmudical time. But if so, it is very strange that Saadjah Gaon, who lived in the tenth, and Judah Halevi, who lived in the twelfth century, represented the book Yetzirah as a very ancient work. ... Tradition, which ascribes the authorship of this book to the patriarch Abraham, is fabulous, as can be proved by many reasons; but the idea that Rabbi Akiva, who lived about the beginning of the second century, composed the book Yetzirah, is very likely possible" [6]. Kalisch concludes telling that a Christian theologian, Johann Friedrich von Meyer remarked in his preface to the book Yetzirah, published in 1830, that the knowledge of it is of great importance to the philosophical inquirers, and cannot be put aside.

Kalisch tells that the system, as it is displayed in the Sefer Yetzirah, forms a link in the chain of the ancient theoretical speculations of philosophers, "who were striving to ascertain the truth mainly by reasoning a-priori, and who imagined that it is thus possible to permeate all the secrets of nature. A first cause, eternal, all-wise, almighty and holy, is the origin and the center of the whole universe, from whom gradually all beings emanated. Thought, speech and action are an inseparable unity in the divine being; God made or created, is metaphorically expressed by the word: writing. ... This self-existing first cause called the creation into existence by quantity and quality; the former represented by ten numbers, Sefirot, the latter by twenty-two letters, which form together thirty-two ways of the divine wisdom. Three of the twenty-two letters, namely, Aleph, Mem, Shin, are the mothers, or the first elements, from which came forth the primitive matter of the world: air, water and fire, that have their parallel in man, (male and female): breast, body and head, and in the year: moisture, cold and heat. The other seven double and twelve simple letters are then represented as stamina, from which other spheres or media of existence emanated. ... God stands in close connection with the Universe, and just so is Tali connected with the world, that is, an invisible, celestial or universal axis carries the whole fabric. In the year by the sphere, in man by the heart, and thus is the ruling spirit of God everywhere" [6].

Here in the following some parts of the book and the corresponding discussions of the translator, form [6]. In some points of the text, however, I used the translation given in [7] too.

\section{The Chapter I of the Sefer}

JAH, the Lord of Hosts, the living God, King of the Universe, Omnipotent, All-Kind and Merciful, Supreme and Extolled, who is Eternal, Sublime and Most-Holy, ordained (formed) and created the Universe in thirty-two mysterious paths of wisdom by three Sepharim (Number, Speech, and Writing), which are in Him one and the same. They consist of a decade out of nothing and of twenty-two fundamental letters. He divided the twenty-two consonants into three divisions: three mothers, fundamental letters or first elements; seven double; and twelve simple consonants.

The decade out of nothing is analogous to that of the ten fingers and toes of the human body, five parallel to five, and in the center of which is the covenant with the only One, by the word of the tongue and the rite of Abraham. Ten are the numbers out of nothing, and not the number nine, ten and not eleven. Comprehend this great wisdom, understand this knowledge, inquire into it and ponder on it, render it evident and lead the Creator back to His throne again. The decade out of nothing has the following ten infinitudes: the beginning infinite, the end, good, evil, height, the depth infinite, the East, West, North, and South; and the only Lord God, the faithful King, rules over all from His holy habitation for ever and ever.

The appearance of the ten spheres out of nothing is like a flash of lightning, being without an end, His word is in them, when they go and return; they run by His order like a whirlwind and humble themselves 
before His throne. The decade of existence out of nothing has its end linked to its beginning and its beginning linked to its end, just as the flame is wedded to the live coal; because the Lord is one and there is not a second one, and before one what wilt thou count?

Concerning the number ten of the spheres of existence out of nothing keep thy tongue from speaking and thy mind from pondering on it, and if thy mouth urges thee to speak, and thy heart to think about it, return! as it reads: "And the living creatures ran and returned", and upon this was the covenant made.

The following are the ten categories of existence out of nothing:

1) The spirit of the living God, praised and glorified be the name of Him who lives to all eternity. The articulate word of creative power, the spirit and the word are what we call the holy spirit is

2) Air emanated from the spirit by which He formed and established twenty-two consonants, stamina. Three of them, however, are fundamental letters, or mothers, seven double and twelve simple consonants; hence the spirit is the first one.

3) Primitive water emanated from the air. He formed and established by it Bohu (water, stones) mud and loam, made them like a bed, put them up like a wall, and surrounded them as with a rampart, put coldness upon them and they became dust, as it reads: "He says to the snow (coldness) be thou earth".

4) Fire or ether emanated from the water. $\mathrm{He}$ established by it the throne of glory, the Seraphim and Ophanim, the holy living creatures and the angels, and of these three He formed His habitation, as it reads: "Who made His angels spirits, His ministers a flaming fire". He selected three consonants IHV from the simple ones which are in the hidden secret of three mothers or first elements: air, water and ether or fire. He sealed them with spirit and fastened them to His great name and sealed with it six dimensions.

5) He sealed the height and turned towards above, and sealed it with IHV

6) He sealed the depth, turned towards below and sealed it with IVH

7) He sealed the east and turned forward, and sealed it with a word HIV

8) He sealed the west and turned backward, and sealed it with a word VHI

9) He sealed the south and turned to the right and sealed it with a word VIH

10) He sealed the north and turned to the left and sealed it with a word HVI

These are the ten spheres of existence out of nothing. From the spirit of the living God emanated air, from the air, water, from the water, fire or ether, from the ether, the height and the depth, the East and West, the North and South.

\section{Notes to Chapter I}

Let us report the notes to this chapter in [6]. As explained by Kalisch, the author of the Sefer maintains that there is a first intelligent, self-existing and almighty, eternal ruling cause of all things, and that an everlasting entity produced nonentities by a progression of effects. This divine knowledge differs from the human knowledge in such a degree, that it gives existence to all that is; it seems to Kalisch that the author of the Sefer not only wanted to contradict Plato's assertion that the Supreme Being had need of a plan, like the human architect, to conduct the great design, when he made the fabric of the Universe, but also the common belief that God reasons and acts by ideas like a human being.

The text in [6] gives the names of the three Sepharim. These names signify: first, number, calculation or idea; second, the word; third, the writing of the word. The idea, word and writing (of the word), means that there is an ideal world in the divine intellect, according to which this sensible world was made. In this cosmogony, "there has not been any matter or hyle existing from all eternity, containing different kinds of primitive atoms or molecules etc., as the Greek philosopher, Anaxagoras, taught, but that all things are the gradual emanations of one everlasting being". In God is the beginning and he is the boundary of the Universe.

A decade describes the steps of the creation, "like Pythagoras, who taught that the digits inclusive number ten which are typified in Tetraktys, namely: 1 plus 2 plus 3 plus 4 equal 10, and which comprise the whole arithmetical system of nature, etc. Our author endeavors to show the gradual emanation of all things from God, which were completely finished in ten spheres". In the cosmogony of Grosseteste [4], we find again 10 spheres, and 10 as the perfect number. That is, we find the Tetraktys. As the infinite series of numbers starts from one unit, so was the whole Universe formed a unity, that centers in the Godhead. In Grosseteste we find also the appearance of the ten spheres out of nothing, like a flash of lightning. According to the medieval philosopher, it is the light in them, which is working as the word of God, "when they go and return" as told in the Sefer.

According to the author of the Sefer, the space and six dimensions emanated from the ether. Judah Halevi, in his book entitled "Kusari", tells that "the Creator is one, and the space has in the figurative expression six dimensions. The book Yetzirah, having ascribed to the Creator some names in the spiritual language, chooses now in the human language the finest sounds which are, as it were, the 
spirits of the other sounds, namely: IHV and says, that when the divine will was expressed by such a sublime name, it became that which the Exalted by praise wished to call forth according to the combination of IHV ". Hence it follows, that the material world was created by their combinations and out of each of them became one dimension of the world, the "sphere". There are ten spheres of existence out of nothing. From the spirit of the living God emanated air, from the air, water, from the water, fire or ether, from the ether, the height and the depth, the East and West, the North and South.

\section{From Chapter II and III of the Sefer}

There are twenty-two letters, stamina. Three of them, however, are the first elements, fundamentals or mothers, seven double and twelve simple consonants. The three fundamental letters have as their basis the balance ..... The twenty-two letters which form the stamina, after having been appointed and established by God, He combined, weighed and changed them, and formed by them all beings which are in existence, and all those which will be formed in all time to come. He established twenty-two letters, stamina, by the voice, formed by the breath of air and fixed them on five places in the human mouth, namely: gutturals, palatals, linguals, dentals, and labials.

He fixed the twenty-two letters, stamina, on a sphere, like on a wall, with two hundred and thirty-one gates, and turned the sphere forward and backward. ... He created a reality out of nothing, called the nonentity into existence and hewed, as it were, colossal pillars from intangible air. This has been shown by the example of combining the letter Aleph with all the other letters, and all the other letters with Aleph. He predetermined, and by speaking created every creature and every word by one name. For an illustration may serve the twenty-two elementary substances by the primitive substance of Aleph.

The three first elements, ... three mothers, Aleph, Mem, Shin, are a great, wonderful and unknown mystery, and are sealed by six rings, or elementary circles, namely: air, water and fire emanated from them, which gave birth to progenitors, and these progenitors gave birth again to some offspring. God appointed and established the three mothers, combined, weighed and changed them, and formed by them three mothers in the world, in the year and in man, male and female.

The three mothers Aleph, Mem, Shin in the world are: air, water and fire. Heaven was created from fire or ether; the earth (comprising sea and land) from the elementary water; and the atmospheric air from the elementary air, or spirit, which establishes the balance among them. The three mothers produce in the year: heat, coldness and moistness. Heat was created from fire, coldness from water, and moistness from air which equalizes them. ... In the first division, God let the letter Aleph predominate in primitive air, crowned it, combined one with the other, and formed by them the air in the world, moistness in the year, and the breast in man, male and female. ... In the second division, He let the letter Mem predominate in primitive water, and crowned it, combined one with the other, and formed by them the earth, (including land and sea) coldness in the year, and the belly in male and female. In the third division, $\mathrm{He}$ let the letter Shin predominate in primitive fire, crowned it, combined one with the other, and formed by them, heaven in the world, heat in the year, and the head of male and female.

\section{Notes to Chapters II and III}

Isidor Kalisch explains that the "ancient philosophers maintained that if God is the first cause, and $\mathrm{He}$ is necessarily, He, the immediate effect of Him, as an absolute unity, can only be again a unity. Hence from a being that is in every respect a unique being, there can only emanate one being; because would two essentially and truly different things issue conjointly from one being, they can only proceed from two different things of substance, that would consequently admit a division that is inconceivable. They then put the question, how came so many various beings into existence? Our author is therefore endeavoring to show that the whole universe emanated gradually from the spirit of the one living God. God, his idea and his word are a unity; hence the author signifies by the letter Aleph the air from which emanated the creative speech, etc. Here is meant: ethereal air, ethereal water, ethereal fire, the macrocosm, the courses of time and microcosm" [6]. Many offspring or derivations came from the latter three, as their progenitors, as it is explained in the chapter.

\section{From Chapters IV, V and VI of the Sefer}

The seven double letters, Beth, Gimel, Daleth, Kaph, $\mathrm{Pe}$, Resh, Tau, with a duplicity of pronunciation, aspirated and unaspirated, serve as a model of softness and hardness, strength and weakness. Seven double letters ... symbolize wisdom, wealth, fruitfulness, life, dominion, peace and beauty. Seven double letters serve to signify the antithesis to which human life is exposed. The antithesis of wisdom is foolishness; of wealth, poverty; of fruitfulness, childlessness; of life, death; of dominion, dependence; of peace, war; and of beauty, ugliness. The seven double consonants are analogous to the six dimensions: height and depth, East and West, North and South, and the holy temple that stands in the center, which carries them all. The double consonants are seven, and not six, they are seven and not eight; reflect upon this fact, inquire about it, and make it so 
evident, that the Creator be acknowledged to be on His throne again.

The seven double consonants, stamina, having been designed and established, combined, weighed, and changed by God, He formed by them: seven planets in the world, seven days in the year, seven gates, openings of the senses, in man, male and female. The seven planets in the world are: Saturn, Jupiter, Mars, Sun, Venus, Mercury, Moon. Seven days in the year are the seven days of the week; seven gates in man, male and female, are: two eyes, two ears, two nostrils and the mouth.

In the first division, $\mathrm{He}$ let the letter Beth predominate in wisdom, crowned it ,combined one with the other and formed by them :the moon in the world ,the first day in the year, and the right eye in man, male and female. In the second division, ... By the seven double consonants, were also designed seven worlds, seven heavens, seven lands, (probably climates,) seven seas, (probably around Palestine,) seven rivers, seven deserts, seven days a week, seven weeks from Passover to Pentecost, there is a cycle of seven years, the seventh is the release year, and after seven release years is jubilee. Hence, God loves the number seven under the whole heaven. (In the whole nature.)

The twelve simple letters (He, Vau, Zain, Heth, Teth, Yod, Lamed, Nun, Samech, Oin, Tzaddi, and Quoph) symbolize, as it were, the organs of speaking, thinking, walking, seeing, hearing, working, coition, smelling, sleep, anger, swallowing and laughing. The twelve simple consonants symbolize also twelve oblique points: east height, north east, east depth, south height, south east, south depth, west height, south west, west depth, north height, north west, north depth. They grew wider and wider to all eternity, and these are the boundaries of the world.

The twelve simple letters stamina, having been designed, established, combined, weighed and changed by God, He performed by them: twelve constellations in the world, twelve months in the year, and twelve leaders (organs) in the human body, male and female. The twelve constellations in the world are: Aries, Taurus, Gemini, Cancer, Leo, Virgo, Libra, Scorpio, Sagitarius, Capricornus, Aquarius and Pisces. The twelve months of the year are: Nisan, Iyar, Sivan, Tamus, Ab, Elul, Tishri, Marcheshvan, Kislev, Teves, Schevat and Adar. ... In the first division, God let the letter He predominate in speaking, crowned it ,combined one with the other, and formed by them :Aries )the Ram (in the world, the month Nisan in the year, and the right foot of the human body, male and female. In the second division, God let the letter Vau predominant in Mind, ... (and so on for each of the twelve letters).
These are the three mothers or the first elements, Aleph, Mem, Shin, from which emanated three progenitors; primitive air, water and fire, and from which emanated as their offspring, three progenitors and their offspring, namely: the seven planets and their hosts, and the twelve oblique points. To confirm this there are faithful witnesses; the world, year and man, the twelve, the Equipoise, the Heptade, which God regulates like the Dragon, (Tali) sphere and the heart. The first elements are air ,water and fire ; the fire is above, the water below, and a breath of air establishes the balance among them. ... The Dragon (Tali) is in the world like a king upon his throne, the sphere is in the year like a king in the empire, and the heart is in the human body like a king in war. ... There are twenty-two letters by which the I am, JAH, the Lord of Hosts, Almighty and Eternal, designed, formed and created by three Sepharim, His whole world, and formed by them creatures and all those that will be formed in time to come.

When the patriarch Abraham comprehended the great truism, revolved it in his mind, conceived it perfectly, made careful investigations and profound inquiries, pondered upon it and succeeded in contemplations, the Lord of the Universe appeared to him, called him his friend, made with him a covenant between the ten fingers of his hands, which is the covenant of the tongue, and the covenant between the ten toes of his feet, which is the covenant of circumcision, and said of him: "Before I formed thee in the belly I knew thee."

\section{Discussion}

According to the Sefer, Kalisch explains, from the unity of God emanated three ethereal elements: primitive air from the spirit, primitive water from the air, and from the water, the primitive fire or ether, "out of which came other spheres of existence in the significant and highly important number, seven, from which descended smaller spheres and which produced again others". So the ideal became, after numerous emanations, more condensed, palpable and concrete. "The whole creation is thus contemplated as a pyramid, terminating in a point at the top with a broad basis" [6].

The order of the planets, including the Sun, is stated in the Sefer according to the Ptolemaic system which was in vogue till the middle of the fifteenth century, namely: Moon, Mercury, Venus, Sun, Mars, Jupiter and Saturn. But this arrangement could be an interpolation of a later time, if the author of the Sefer lived many years before Ptolemy. For what concerns the dragon Tali, Kalisch tells that some argued by this expression is "understood the constellation Draco or Dragon, which is a very large constellation extending for a great length from East to West, beginning at the tail which lies half way between the Pointers and the 
Pole Star, and winding round between the Great and Little Bear ... Dr. Cassel (in his commentary to the book entitled Kusari) is of the opinion that our author meant here, probably the invisible, celestial or universal axis that carries the whole Universe" [6].

As told in [10], the Sefer Yetzirah was perhaps one of the most influential works in medieval Jewish cosmology. The Jewish philosophers, facing with a variety of philosophical cosmogonies, commented extensively upon Sefer Yetzirah, to solve the question of the origin and structure of the world. There is therefore a rich commentary tradition, even on the astrological passages of the Sefer. Saadia Gaon and Shabbetai Donnolo wrote extensively on the Sefer: Gaon wrote an Arabic treatise in the late ninth or early tenth century, whereas Donnolo worked in the tenth century. Ibn Gabirol refers indirectly to the book too, when he describes the universe as an emanation of God: "He who dwelleth forever, exalted is he alone from the yore Solitary in his royal grandeur is he, and there is none by his side From the light in which he is cloaked he fashioned the universe In the manner of the three sealed books" [10].

In fact, the Sefer Yetzirah offers two systems of cosmology [11], one based on the ten primordial numbers, or principles, the Sefirot, the other based on the twenty-two letters of the Hebrew alphabet. "The former inspired the medieval mystical cosmogonies, the latter lies behind much medieval mystical praxis which involves manipulating the letter of the Hebrew alphabet. The work is usually thought to have been written in Palestine in the third or fourth century CE, but it could be dated to almost any century between the second and the seventh". Reference 11 explains that, although the medieval mystics believed it containing a mystical doctrine, it is unlikely that its author intended it so. It could be "a work of science an attempt to explain in rational terms the structure of reality". That is, this book proposed a sort of atomistic theory, where the complexity is derived from the different combinations and permutations of the letters of the alphabet [11].

Let us conclude our discussion with what is reported in the introduction to his translation [7], because it is good for a comparison to the Grosseteste's metaphysics of the first form and matter [4]. In [7], it is told that a French scholar, Adolphe Franck, wrote in his volume on the Kabbalah that in the Sefer we have "the substitution of the absolute divine Unity for every idea of Dualism, for that pagan philosophy which saw in matter an eternal substance whose laws were not in accord with Divine Will; and for the Biblical doctrine, which by its idea of Creation, postulates two things, the Universe and God, as two substances absolutely distinct one from the other. In fact, in the Sefer Yetzirah, God considered as the Infinite and consequently the indefinable Being, extended throughout all things by his power and existence, is while above, yet not outside of numbers, sounds and letters - the principles and general laws which we recognize. Every element has its source from a higher form, and all things have their common origin from the Word (Logos), the Holy Spirit.... So God is at once, in the highest sense, both the matter and the form of the universe. Yet He is not only that form; for nothing can or does exist outside of Himself; His substance is the foundation of all, and all things bear His imprint and are symbols of His intelligence". As previously told, these words are relevant to understand the framework supporting the Grosseteste's metaphysics of the first form.

\section{References}

[1] Vv. Aa., Wikipedia, http://en.wikipedia.org/wiki/Sefer_Yetzirah

[2] Yetzirah, Sefer, in Jewish Encyclopedia, 1901-1906.

[3] A. Kaplan, Sefer Yetzirah: The Book of Creation In Theory and Practice, San Francisco, Weiser Books, 1997.

[4] A.C. Sparavigna, Robert Grosseteste's Thought on Light and Form of the World, The International Journal of Sciences, 2014, Volume 3, Issue 4, pp. 54-62.

[5] A.C. Sparavigna, The Generation of Sounds According to Robert Grosseteste, The International Journal of Sciences, 2013, Volume 2, Issue 10, pp. 1-5.

[6] Sefer Yetzirah, translated by Isidor Kalisch, 1877, in Sacred Texts, at www.sacred-texts.com/jud/sy/index.htm

[7] Sefer Yetzirah or the Book of Creation, translated by W.W. Wescott, 1877, in Sacred Texts, at www.sacredtexts.com/jud/yetzirah.htm

[8] E. Morlok, Rabbi Joseph Gikatilla's Hermeneutics, Mohr Siebeck, 2011.

[9] S. Pines, Points of Similarity between the Exposition of the Doctrine of the Sefirot in the Sefer Yetzura and a Text of the Pseudo-Clementine Homilies: The Implications of this Resemblance, in eds. W.Z. Harvey and M. Idel, Studies in the History of Jewish Thought by Shlomo Pines, Jerusalem 1997.

[10] T.M. Rudavsky, Time Matters: Time, Creation, and Cosmology in Medieval Jewish Philosophy, SUNY Press, 2000.

[11] M. Goodman, J. Cohen and D. Sorkin, The Oxford Handbook of Jewish Studies, Oxford Handbooks Online, 2002. 